\title{
New perspectives of volemic resuscitation in polytrauma patients: a review
}

\author{
Ovidiu Horea Bedreag ${ }^{1,2}$, Marius Papurica ${ }^{1,2}$, Alexandru Florin Rogobete ${ }^{1,2,4^{*}}$ (D) Mirela Sarandan ${ }^{3}$, \\ Carmen Alina Cradigati ${ }^{3}$, Corina Vernic ${ }^{2}$, Corina Maria Dumbuleu ${ }^{1}$, Radu Nartita ${ }^{4}$ and Dorel Sandesc ${ }^{1,2}$
}

\begin{abstract}
Nowadays, fluid resuscitation of multiple trauma patients is still a challenging therapy. Existing therapies for volume replacement in severe haemorrhagic shock can lead to adverse reactions that may be fatal for the patient. Patients presenting with multiple trauma often develop hemorrhagic shock, which triggers a series of metabolic, physiological and cellular dysfunction. These disorders combined, lead to complications that significantly decrease survival rate in this subset of patients. Volume and electrolyte resuscitation is challenging due to many factors that overlap. Poor management can lead to post-resuscitation systemic inflammation causing multiple organ failure and ultimately death. In literature, there is no exact formula for this purpose, and opinions are divided. This paper presents a review of modern techniques and current studies regarding the management of fluid resuscitation in trauma patients with hemorrhagic shock. According to the literature and from clinical experience, all aspects regarding post-resuscitation period need to be considered. Also, for every case in particular, emergency therapy management needs to be rigorously respected considering all physiological, biochemical and biological parameters.
\end{abstract}

Keywords: Multiple trauma, Fluid resuscitation, Intensive care, Electrolyte imbalance

\section{Background}

Multiple trauma patient represents a challanging case in the intensive care unit (ICU). Severe systemic inflamatory syndrome trigger multiple biochemical and physiological dysfunctions resulting in a significant decrease in survival rate $[1,2]$. Special attention is given to hemorrhagic shock $[3,4]$. Volume replacement is often defining the clinical evolution of these patients. Impaired tissue oxygenation caused by insufficient perfusion has direct implications in anaerobic metabolism, inflammation and ultimately multiple organ dysfunctions syndrome (MODS) $[5,6]$. Moreover, cellular and tissue hypoxia lead to abnormal celullar metabolism accompanied by redox imbalances. Mitochondrial dysfunction, release of pro-inflammatory molecules, cell adhesion factors, metabolites resulting from cell destruction are all responsible for synthesis of a significant amounts of free radicals (FR) [7] that can lead to the phenomenon called oxidative stress (OS) [8]. The best-

\footnotetext{
* Correspondence: alexandru.rogobete@umft.ro

${ }^{1}$ Clinic of Anaesthesia and Intensive Care, Emergency County Hospital "Pius

Brinzeu", Bd. losif Bulbuca nr.10, Timisoara, Timis, Romania

${ }^{2}$ Faculty of Medicine, "Victor Babes" University of Medicine and Pharmacy,

Timisoara, Romania

Full list of author information is available at the end of the article
}

known FR present in trauma patients are represented by hydroxyl radical, superoxide radical, hydrogen peroxide, nitroperoxide. The main sources of FR are represented by mitochondria, xanthine oxidase, nicotinamide adenine dinucleotide phosphate $\mathrm{NAD}(\mathrm{P}) \mathrm{H}$ oxidase, as well as a number of endothelial factors $[9,10]$.

Fluid therapy can be achieved by administering blood products and substitutes, crystalloid solutions (low molecular weight molecules able to cross the semi-permeable membranes) or colloidal solutions (high molecular weight molecules, unable to cross the semipermeable membrane) [11-13]. Most clinical studies are inconsistent regarding the use of solutions for volume replacement in hemorrhagic shock resuscitation. If some authors recommend crystalloid solutions, others recommend colloidal solutions, blood and blood product or mixed with different biologically active substances [14]. In this update has the propose, following a thorough literature review, to present current methods and implications of volume resuscitation in patients with multiple trauma. 


\section{Review}

\section{Pathophysiology of hemorrhagic shock}

Water sector disorders occur within well defined pathological situations. Losing large amounts of blood after multiple trauma leads to hypovolemia $[15,16]$. Decreased extracellular compartment is partially compensated by transferring ionic liquids from the intracellular compartment (especially $\mathrm{K}^{+}$) [17]. The ultimate result of this state of self-compensation is global isotonic dehydration with hyperkalemia with a high risk of rapid hemodynamic decompensation. At the cellular level, tissue hypoperfusion causes anaerobic glycolysis producing lactate and reduced functional capacity of cells leading to death by necrosis or apoptosis [18]. Also, studies in laboratory animals have shown that the type of solutions used in resuscitation directly influence apoptosis in various tissues $[19,20]$. One of the most significant side effects of hemorrhagic shock is represented by systemic inflammatory response syndrome (SIRS), appeared within hours post-trauma, being responsible for increased capillary permeability, release of proinflammatory factors, and release of highly reactive molecular species [19]. The levels of electrolytes with extremely high physiological importance are affected in hypovolemic shock. Altered electrolyte balance entails a multitude of cellular dysfunction with serious repercussions upon the patient in shock. After hemorrhagic shock, microcirculation shows significant dysfunction caused by capillary collapse, leading to decreased functionality and decreased tissue $\mathrm{pO}_{2}$ [20]. Nitric oxide (NO) is directly involved in pressure redistribution, a phenomenon explained by the ability to relax blood vessels [20]. For proper monitoring of patients with multiple trauma, studies recommend analyzing a series of parameters including temperature, skin perfusion, urine output, invasive blood pressure, heart rate, inflamatory markers and ABG parameters [21]. Following resuscitation fluids, even if macro-hemodynamic changes are favorable, the micro-hemodynamic changes can remain deficient. To monitor microvascular system, a parameter widely studied is the central venous oxygen saturation $\left(\mathrm{ScvO}_{2}\right)$ [22]. $\mathrm{ScvO}_{2}$ is an important marker that shows the balance between oxygen delivery and oxygen consumption. However, $\mathrm{ScvO}_{2}$ monitoring may be misleading, particularly in regions with severe tissue hypoxia. To optimize fluid therapy based on microvascular system functionality, another parameter represented by central-venous-to-arterial $\mathrm{CO}_{2}$ difference was introduced $\left(\mathrm{CO}_{2}\right.$ gap) $[22,23]$. Physiologically, $\mathrm{CO}_{2}$ gap should be less than $5 \mathrm{mmHg}$. Studies have reported values above $5 \mathrm{mmHg}$ in sepsis, severe hypovolemia and ischemia reperfusion syndrome. Elevated $\mathrm{CO}_{2}$ gap is associated with MODS and poor prognosis in critical patients [23, 24]. Usually tachycardia occurs due to vascular collapse and represents a compensatory physiological effects. Recently, it was shown that there may be special circumstances in this respect, when bradycardia occurs due to increased parasympathetic tone [25]. Lactic acidosis is a good indicator of tissue hypoxia even if vital signs are normal. Decreased lactate and lactic acidosis correction means restoring proper blood flow [26]. Base deficit represents one of the most important parameters in monitoring patients with multiple trauma and hemorrhagic shock. Base excess (BE) less than $-6 \mathrm{mmol} / \mathrm{L}$ indicates a possible intra-abdominal disease with massive blood loss or acute pulmonary failure [27]. Moreover there is a strong relationship between mortality and base excess in patients with multiple trauma and blood loss more than $50 \%$ [28]. In addition, the following parameters are recommended to be monitored - mixed venous oxygen saturation, venous-arterial $\mathrm{CO}_{2}$ partial pressure, central venous pressure, pulmonary artery occlusion pressure, gastric tonometry or sublingual capnography [29].

\section{New ideas for volume replacement}

The highest mortality rate in trauma patients is due to hemorrhagic shock and incorrect volume resuscitation [30]. Resuscitation is recommended to be guided by several clinical aspect, such as vital signs, urine output, perfusion, acid-base imbalance, immune function, extracellular matrix production and cell chemotaxis, ability to prevent cerebral edema, pulmonary edema [15]. The most important factor at the cellular level is the exchange pump $\mathrm{Na}^{+} / \mathrm{H}^{+}$[31]. Wu et al., in a study conducted on a group of 24 pigs demonstrated that by blocking the pump $\mathrm{Na}^{+} / \mathrm{H}^{+}$and thus reducing the level of lactic acid could protect cellular alteration [31]. Ischemia and reperfusion is an important precursor in the inflammatory processes that are responsible for producing oxygenated reducing agents. Saad et al., showed that the most affected in this regard are the lungs [32]. Impaired lung function is caused by deposits of fibrin, alveolar hemorrhage, interstitial fluid or neutrophil sequestration [32]. These combined lead to respiratory distress syndrome. Increased inflammatory response is stimulated by the presence of biochemical markers such as, interleukin 6 (IL-6), FR, which, biochemically has increased affinity to alveolar macrophages [7, 33]. Another important biochemical marker in this sense is tumor necrosis factor aflpha (TNF-alpha) which is produced 1-2 hours after hemorrhagic shock and is often associated with organ damage [34].

\section{Antioxidant therapy in volemic resuscitation}

Numerous studies demonstrate that administration of antioxidants along with fluids leads to progressive increase in the rate of survival by significantly reducing oxidative stress and inflammatory response [35]. Numerous studies recommend administering substances with antioxidant capacity both in the first 24 hours post-trauma, as well as during the ICU admission. The most commonly used antioxidants are vitamin C, B, Selenium, N-acetylcysteine and resveratrol 
$[14,36]$. Juretic et al., studied the implications of vitamins $\mathrm{A}, \mathrm{C}$ and $\mathrm{E}$ on the inflammatory status. Following concomitant administration of $38 \mathrm{mg} / \mathrm{kg}$ Vitamin C (i.v.), $27 \mathrm{U} / \mathrm{kg}$ Vitamin E (i.v.) and $41 \mathrm{U} / \mathrm{kg}$ Vitamin A (i.v.), the group of animals who received antioxidant therapy showed significant reductions in inflammation and cardiovascular function potentiation [7]. Lloberas et al., studied the effects of administered vitamin $\mathrm{C}$ in laboratory animals with hemorrhagic shock. They reported improved kidney function and reduced systemic inflammation [37]. Another biologically active compound used as an adjunct to volume replacement solutions with outstanding results is Centhaquin. Ringer's lactate solution is effective in restoring hemodynamic parameters, but has a number of physiological limitations. Lavhale et al., have shown that the use of hypertonic saline solution with Centhaquin significant decreases the lactate concentration and support the increase and maintenance of mean arterial pressure [38]. He reports that the use of $0.05 \mathrm{mg} / \mathrm{kg}$ of Centhaquin is indicated for correct volume expansion [38]. The phenomenon is explainable by the pharmacological properties that it owns - central sympathetic activity and vasoconstriction, resulting in improved tissue reperfusion through cardiovascular control [38]. Numerous studies recommend glutamine as antioxidant in critical patients. However, there are a series of side effects after high doses of glutamine. Daren et. al performed a study in 40 intensive care units from Europe and North America and emphasized a direct correlation between glutamine administration and MODS incidence. [39].

Aksu et al., explained the benefits of volume resuscitation when using gluconate - balanced crystalloid which prevent hyperchloraemic acidosis, anion gap and renal hypoperfusion [40]. They highlighted the decline in tissue inflammation but also the increase of favorable parameters for volume and electrolyte balance [40]. Another intense studied compound is decay accelerating factor (CD55/ DAF) [30]. It is a membrane protein that has enzymatic action, protecting the cells of antologous complement activation. Lucca et al., conducted a study in which hemorrhagic shock resuscitation was performed using recombinant human DAF. Histological analysis demonstrated that the use of DAF $(50 \mathrm{mg} / \mathrm{kg})$ in volume replacement solutions reduce particulary renal and hepatic injuries. In addition to these benefits, the use of DAF reduces the need for fluids and prevents inflammatory responses and coagulopathy [30]. A biologically active compound used in combination with fluids is valproic acid [41]. Hemorrhagic shock blocks histone acetyltransferase activity, suppressing gene transcription. Valproic acid acts upon histone deacetylase inhibitor [41, 42]. Glycogen Synthase Kinase (GSK) [43, 44] is a biologically active substance used in the management of fluid resuscitation. This enzyme regulates a number of cellular functions protein synthesis, cell differentiation and cell motility. Overexpression of GSK lead to an extremely complex inflammatory phenomenon [43]. Recent studies show that by blocking the activity of GSK-3-Beta, inflammation and hepatocellular injury markers decrease significantly. To inhibit the activity of this enzyme, Jellestad et al., used two agents: 4-benzyl-2-methyl1,2,4-thiadizolidine 3,5-diones (TDZD-8) [34] and domethyl sulfoxide (DMSO). In the study they demonstrated that inhibition of GSK-3-Beta enzyme leads to increased liver function and microcirculation [43].

\section{Fluid resuscitation and inflammatory and redox status}

Fluid management in trauma patients is extensively studied, and controversies regarding side effects, inflammatory response and tissue hypoxia further complicate the clinical decisions. Table 1 presents studies related to fluid management in critical patients.

German Society for Trauma Surgery recommends using Ringer's solution acetated or malate Ringer's solution before the start of volume resuscitation. The metabolism of acetate prevents hyperchloraemic acidosis, being metabolized to carbon dioxide and water. Meanwhile, acetate molecule can be metabolized in gluconeogenesis, forming bicarbonate ion $\left(\mathrm{HCO}_{3}^{-}\right)$. For each functional group in acetate molecule $(\mathrm{COOH})$, one $\mathrm{HCO}_{3}^{-}$molecule is

Table 1 Fluid resuscitation studies

\begin{tabular}{|c|c|c|c|}
\hline Author & Type of fluid & Observations & Reference \\
\hline O’Malley et al. & $\mathrm{NaCl} 0.9 \%$, respective lactated Ringer & $\begin{array}{l}\text { They noticed that when using lactated Ringer solution, the incidence of } \\
\text { patients with hyperkalemia decreases, as well as incidence of acidosis. }\end{array}$ & {$[65]$} \\
\hline Maitland et al. & Albumine, respective $\mathrm{NaCl} 0.9 \%$ & In both cases there was an increase in mortality rate. & {$[66]$} \\
\hline Shaw et al. & $\mathrm{NaCl} 0.9 \%$, respective balanced crystalloid & $\begin{array}{l}\text { When using } \mathrm{NaCl} 0.9 \% \text { there was an increase in mortality rate and } \\
\text { ABG imbalances. }\end{array}$ & {$[67]$} \\
\hline Annane et al. & $\begin{array}{l}\text { Comparison between colloids and } \\
\text { cristaloides. }\end{array}$ & There was no statistically significant difference between the two groups. & {$[68]$} \\
\hline Rasmussen et al. & $\begin{array}{l}\text { Studied the effects of HES 130/0.4 } \\
\text { upon coagulation }\end{array}$ & $\begin{array}{l}\text { They noticed reduced clot strength. It also showed a decrease in fluid } \\
\text { requirements. }\end{array}$ & {$[69]$} \\
\hline Abeed et al. & $\begin{array}{l}\text { Studied the renal function after } \mathrm{NaCl} \\
0.9 \% \text { vs. Plasma-Lyte } 148\end{array}$ & $\begin{array}{l}\text { There was a decrease renal blood flow and renal cortical tissue perfusion } \\
\text { in case of } \mathrm{NaCl} 0.9 \% \text { administration. }\end{array}$ & {$[70]$} \\
\hline
\end{tabular}


produced. Biochemical reaction occurs mainly in muscle and liver. Röhring et al., have examined this recommendation, demonstrating that after induction of hemorrhagic shock in laboratory mice, the use of acetated Ringer's solution achieved a successful resuscitation level [45]. During shock, arterial $\mathrm{pH}$ was in average around 7.2. Administration of acetated Ringer's solution, unlike saline, resulted in significantly higher $\mathrm{pH}$. The TNF-alpha and IL-6 had lower values [45].

Recent international guidelines and protocols suggest administration of pressor substances in order to ensure tissue perfusion. Such an agent is arginine vasopressin, with antidiuretic and suppressor of NO synthesis. A lot of studies recommend using vasopressin due to reduced side effects, but also because it brings beneficial effects in fluid management [46].

A negative factor post-resuscitation is the volume of fluid administered intravenously per unit time [47]. Yu et al., have studied post-resuscitation differences after performing slow resuscitation (12 hours) and rapid resuscitation (30 minutes) [48]. Slow and continuous resuscitation decrease proinflammatory cytokine, microvascular damage and hypoalbuminemia. At the same time pulmonary disorders are less often encountered [48].

A major problem during fluid resuscitation is ensuring the functionality of microvascular system. Impaired capillary system leads to tissue hypoxia, responsable of inflammation, mitochondrial dysfunctions, increased FR and cellucar apoptosis. Dubin et al. studied the effects of different types of fluids upon microvascular system in septic patients. The fluids used in the study were HES 130/0.4 and $\mathrm{NaCl} 0.9 \%$. They reported an increased capillary microvenous flow index and perfused capillary density in patients who received HES 130/0.4 [49]. Wang et al., demonstrated that the use of whole blood instead of saline solutions reduce the inflammatory response of the lung tissue [50].

One aspect leading to complicated post-resuscitation evolution and also to lower survival rate is delayed resuscitation [51]. Chien et al., studied the effects occurring by delaying resuscitation. Thus, they followed the activation profile of cytokines according to the delay time in laboratory animals suffering from hemorrhagic shock. After analyzing the results, they reported increased levels of IL6 if resuscitation started after 45-60 minutes after hemorrhagic shock [52].

An important trauma that causes haemorrhagic shock is traumatic brain injury [53]. Studies have shown that in the case of severe brain injury, the main cause of death is massive haemorrhage $[54,55]$. Standard treatment for volume replacement is rapid administration of the crystalloid solutions. It is demonstrated that this method of resuscitation with saline isotons, affects patient due to ischemic brain injury and haemodilution [56].
A pharmaceutical compound found in broad based research is haemoglobin oxygen carriers (HBOCs) described in the literature as the most ideal restoring tissue perfusion [57]. Such a complex is HBOC-201-polymerised bovine HBOC [58]. Curry et al., simulated in the laboratory a 30 minutes pre-hospital time. During this time, the complex HBOC-201 is administered for resuscitation. Histological and laboratory tests have shown that the infusion of this complex increase cerebral oxygenation and perfusion while renal failure and acute lung injury were minimized [58].

There are a number of controversies and contradictory opinions regarding the management of patients with burns. In patients with major burns, volume replacement involves extra attention due to increased electrolyte imbalances and biochemical/biophysical dysfunctions [59] hypovolemic organ failure, incidence of shock, acute renal disease, lung failure by altering the ventilation/perfusion ratio, digestive tract dysfunction by bacterial translocation or erythrocyte hemolysis by membrane hyperoxidation [60]. There is also a generalized alteration of cell membranes. Fluid administration should be adjusted according to each patient depending on the biological and physiological results [61]. Arlati et al., reported that patients with major burns who received Parkland formula developed multiple organ dysfunction more quickly as opposed to permissive hypovolemia and mean arterial pressure of $70 \mathrm{mmHg}$ [62]. A variety of other studies reveal that the Parkland method produces a series of complications acute respiratory distress or abdominal compartment syndrome, and is associated with death in up to $70 \%$ of cases. Hypertonic solutions commonly used in such cases contain $240-300 \mathrm{mEq} / \mathrm{L} \mathrm{Na}^{+}$) resulting in hypernatremia and hyperosmolarity [60].

All these dysfunctions lead to renal dysfunction, intestinal oxidative stress and increased vascular permeability. Increased vascular permeability is a major cause of fluid loss and increased osmotic pressure in the burned tissue, inducing edema and hypoproteinemia. Sun et al, conducted a study on the use of hypertonic saline solution $\left(200 \mathrm{mEg} / \mathrm{L} \mathrm{Na}^{+}\right)$for resuscitation in the laboratory mice with multiple burns. The analyses reported a significant decrease in pulmonary edema incidence. Meanwhile biosynthesis of inflammatory mediators significantly decreases. By lowering the concentration of cytokines, the liver injury is reduced, thus inhibiting cyclooxygenase. The use of such hypertonic solutions $\left(200 \mathrm{mEg} / \mathrm{L} \mathrm{Na} \mathrm{Na}^{+}\right.$, corrects hyponatremia induced by severe burns [60]. Hypoproteinemia accentuate edema, therefore albumin supplementation is required. The altered coagulation disorders are rebalanced by infusion of fresh frozen plasma. Administration of whole blood is not required due to increased viscosity. 
Guidry et al., have studied the differences between the colloid and crystalloid solutions [63]. They recommend lower volumes of colloid and increased volumes of crystalloid to reduce mortality and increase survival rate [63].

Obstetric patients are a real challenge in the event of polytrauma with hemorrhagic shock [64]. Yu et al., conducted a study on pregnant experimental models. The basic idea of the study refers to volume replacement to maintain mean arterial pressure above $60 \mathrm{mmHg}$ [64]. The biological tests performed did not find significant correlations between blood transfusion and prothrombin time, activated partial thromboplastin time and fibrinogen. When using Ringer's solution, significant and positive correlations were revealed regarding prothrombin time and activated partial thromboplastin time and no correlations for fibrinogen [64].

\section{Conclusions}

Hemorrhagic shock has been shown to produce a series of inflammatory reactions affecting cells, biochemical and physiological metabolism and ultimately organ functions. Septic shock, a phenomenon common in most trauma patient, produces severe decompensation in terms of hemodynamics due to low vascular resistance, myocardial dysfunction, oxidative stress, overproduction of NO, microcirculation disorders or excessive activation of $\mathrm{K}^{+}$-ATP sensitive channel. The literature does not offer exact guidelines for fluid resuscitation, and there is a lot of controversy regarding the pros and cons of using colloids or cristalloids. In conclusion, we can say that for each patient there is a resuscitation management to be chosen according to clinical and traumatic status, as well as to the biological and physiological investigations.

\section{Abbreviations}

$\mathrm{pO}_{2}$ : partial pressure of oxygen; NO: nitric oxide; $\mathrm{ABG}$ : arterial blood gases; $\mathrm{BE}$ : base excess; $\mathrm{CO}_{2}$ : carbon dioxide; TNF-alpha: tumor necrosis factor alpha; CD55 / DAF: decay accelerating factor; $\mathrm{COOH}$ : acetate molecule; HES 130/0.4: hydroxyethyl starch; $\mathrm{HCO}_{3}-:$ bicarbonate; IL-6: interleukin 6; GSK: glycogen synthase kinase; TDZD 8: 4-benzyl-2-methyl-1,2,4-thiadizolidine 3,5-diones; DMSO: domethyl sulfoxide; HBOCs: haemoglobin oxygen carriers; ICU: Intensive Care Unit; FR: free radicals; OS: oxidative stress.

\section{Competing interests}

The authors declare that they have no competing interests.

\section{Authors' contributions}

$\mathrm{OHB}, \mathrm{AFR}, \mathrm{RN}$ and MP have made substantial contributions to conception, design, acquisition of data and analysis of data. MS and ACC have been involved in drafting the manuscript and revising it critically for important intellectual content. CMD and AFR have been involved in drafting the manuscript. DS have given final approval of the version to be published. All authors read and approved the final manuscript.

\section{Acknowledgements}

The authors have deeply grateful to Emergency County Hospital "Pius Brinzeu" for full support of this article.

\section{Author details}

'Clinic of Anaesthesia and Intensive Care, Emergency County Hospital "Pius Brinzeu", Bd. losif Bulbuca nr.10, Timisoara, Timis, Romania. ${ }^{2}$ Faculty of Medicine, "Victor Babes" University of Medicine and Pharmacy, Timisoara, Romania. ${ }^{3}$ Clinic of Anaesthesia and Intensive Care "Casa Austria", Emergency County Hospital "Pius Brinzeu", Timisoara, Romania. ${ }^{4}$ Faculty of Chemistry, Biology, Geography, West University of Timisoara, Timisoara, Romania.

Received: 29 April 2015 Accepted: 21 January 2016

Published online: 16 February 2016

\section{References}

1. Aref $\mathrm{H}$, Felemban B. Post traumatic acquired multiple mesenteric defects. Int J Surg Case Rep. 2013;4:547-9.

2. Kuwabara K, Hagiwara A, Matsuda S, Fushimi K, Ishikawa KB, Horiguchi H, et al. A community-based comparison of trauma patient outcomes between d- and I-lactate fluids. Am J Emerg Med. 2013;31:206-14.

3. Morrison JJ, Ross JD, Markov NP, Scott DJ, Spencer JR, Rasmussen TE. The inflammatory sequelae of aortic balloon occlusion in hemorrhagic shock. J Surg Res. 2014;191:423-31.

4. Jungner M, Grände P-O, Mattiasson G, Bentzer P. Effects on brain edema of crystalloid and albumin fluid resuscitation after brain trauma and hemorrhage in the rat. Anesthesiology. 2010;1 12:1194-203.

5. Burkhardt M, Nienaber U, Pizanis A, Maegele M, Culemann U, Bouillon B, et al. Acute management and outcome of multiple trauma patients with pelvic disruptions. Crit Care. 2012;16:R163.

6. Gu W, Jiang J. Genetic polymorphisms and posttraumatic complications. Comp Funct Genomics. 2010;2010:814086.

7. Horton JW. Free radicals and lipid peroxidation mediated injury in burn trauma: the role of antioxidant therapy. Toxicology. 2003;189:75-88.

8. Bar-Or D, Bar-Or R, Rael LT, Brody EN. Oxidative stress in severe acute illness. Redox Biol. 2015;4:340-5.

9. Conti A, Miscusi M, Cardali S, Germanò A, Suzuki H, Cuzzocrea S, et al. Nitric oxide in the injured spinal cord: Synthases cross-talk, oxidative stress and inflammation. Brain Res Rev. 2007;54:205-18.

10. Tinti F, Soory M. Oxidative actions of hydrogen peroxide in human gingival and oral periosteal fibroblasts: Responses to glutathione and nicotine, relevant to healing in a redox environment. Redox Biol. 2014;2:36-43.

11. Kentner R, Safar P, Prueckner S, Behringer W, Wu X, Henchir J, et al. Titrated hypertonic/hyperoncotic solution for hypotensive fluid resuscitation during uncontrolled hemorrhagic shock in rats. Resuscitation. 2005;65:87-95.

12. Rode H, Rogers a D, Cox SG, Allorto NL, Stefani F, Bosco a, et al. Burn resuscitation on the African continent. Burns. 2014;40:1283-91.

13. Perel P, Roberts I, Pearson M, Perel P, Roberts I, Pearson M. Colloids versus crystalloids for fluid resuscitation in critically ill patients. Cochrane Database Syst Rev. 2013;2, CD000567.

14. Oudemans-van Straaten HM, Man A, de Waard MC. Vitamin C revisited. Crit Care. 2014;18:460.

15. Ekerbicer N, Inan S, Tarakci F, Cilaker S, Ozbek M. Histophysiological effects of fluid resuscitation on heart, lung and brain tissues in rats with hypovolemia. Acta Histochem. 2006;108:373-83.

16. Eckerwall $\mathrm{G}$, Olin $\mathrm{H}$, Andersson B, Andersson R. Fluid resuscitation and nutritional support during severe acute pancreatitis in the past: What have we learned and how can we do better? Clin Nutr. 2006;25:497-504.

17. Jauchem JR, Sherry CJ, Fines D a, Cook MC. Acidosis, lactate, electrolytes, muscle enzymes, and other factors in the blood of Sus scrofa following repeated TASER exposures. Forensic Sci Int. 2006;161:20-30.

18. Shires GT, Browder LK, Steljes TPV, Williams SJ, Browder TD, Barber AE. The effect of shock resuscitation fluids on apoptosis. Am J Surg. 2005;189:85-91.

19. Huber-Lang $\mathrm{M}$, Kovtun $\mathrm{A}$, Ignatius $\mathrm{A}$. The role of complement in trauma and fracture healing. Semin Immunol. 2013;25:73-8.

20. Cabrales P. Low dose nitrite enhances perfusion after fluid resuscitation from hemorrhagic shock. Resuscitation. 2009;80:1431-6.

21. Huang Y, Yan B, Yang Z. Clinical study of a formula for delayed rapid fluid resuscitation for patients with burn shock. Burns. 2005;31:617-22.

22. Kocsi S, Demeter G, Erces D, Nagy E, Kaszaki J, Molnar Z. Central venous-toarterial CO2 gap is a useful parameter in monitoring hypovolemia-caused altered oxygen balance: Animal study. Crit Care Res Pract. 2013;2013:583598.

23. Ospina-Tascón G a, Bautista-Rincón DF, Umaña M, Tafur JD, Gutiérrez A, García AF, et al. Persistently high venous-to-arterial carbon dioxide 
differences during early resuscitation are associated with poor outcomes in septic shock. Crit Care. 2013;17:R294.

24. Hernandez G, Luengo C, Bruhn A, Kattan E, Friedman G, Ospina-tascon G a, et al. When to stop septic shock resuscitation : clues from a dynamic perfusion monitoring. Ann Intensive Care. 2014;4:30.

25. Johansson PI, Ostrowski SR. Acute coagulopathy of trauma: Balancing progressive catecholamine induced endothelial activation and damage by fluid phase anticoagulation. Med Hypotheses. 2010;75:564-7.

26. McCague A, Bowman N, Wong DT. Lactic acidosis after resuscitation with sodium acetate. J Surg Res. 2012;173:362-4.

27. Tai SMM, Buddhdev P, Baskaradas A, Sivarasan N, Tai NRM. Venous thromboembolism in the trauma patient. Orthop Trauma. 2013;27:379-92

28. Teranishi K, Scultetus A, Haque A, Stern S, Philbin N, Rice J, et al. Traumatic brain injury and severe uncontrolled haemorrhage with short delay prehospital resuscitation in a swine model. Injury. 2012:43:585-93.

29. Matsuno WC, Yamamoto LG. Terminology used to describe volume expanding resuscitation fluid. Resuscitation. 2006:68:371-7.

30. Dalle Lucca JJ, Li Y, Simovic MO, Slack JL, Cap A, Falabella MJ, et al. Decayaccelerating factor limits hemorrhage-instigated tissue injury and improves resuscitation clinical parameters. J Surg Res. 2013;179:153-67.

31. Wu D, Russano K, Kouz I, Abraham WM. NHE1 inhibition improves tissue perfusion and resuscitation outcome after severe hemorrhage. J Surg Res. 2013:181:e75-81.

32. Saad KR, Saad PF, Dantas Filho L, De Brito JM, Koike MK, Zanoni FL, et al. Pulmonary impact of $\mathrm{N}$-acetylcysteine in a controlled hemorrhagic shock model in rats. J Surg Res. 2013;182:108-15.

33. Chuang TY, Chang HT, Chung KP, Cheng HS, Liu CY, Liu YC, et al. High levels of serum macrophage migration inhibitory factor and interleukin 10 are associated with a rapidly fatal outcome in patients with severe sepsis. Int J Infect Dis. 2014;20:13-7.

34. Chen H, Koustova E, Shults C, Sailhamer E a, Alam HB. Differential effect of resuscitation on Toll-like receptors in a model of hemorrhagic shock without a septic challenge. Resuscitation. 2007;74:526-37.

35. Ogilvie MP, Pereira BMT, McKenney MG, McMahon PJ, Manning RJ, Namias N, et al. First Report on Safety and Efficacy of Hetastarch Solution for Initial Fluid Resuscitation at a Level 1 Trauma Center. J Am Coll Surg. 2010;210:870-80.

36. Lagouge M, Argmann C, Gerhart-Hines Z, Meziane H, Lerin C, Daussin $F$, et al. Resveratrol Improves Mitochondrial Function and Protects against Metabolic Disease by Activating SIRT1 and PGC-1a. Cell. 2006:127:1109-22.

37. Lloberas N, Torras J, Herrero-Fresneda I, Cruzado JM, Riera M, Hurtado I, et al. Postischemic renal oxidative stress induces inflammatory response through PAF and oxidized phospholipids. Prevention by antioxidant treatment. FASEB J. 2002;16:908-10.

38. Lavhale MS, Havalad S, Gulati A. Resuscitative effect of centhaquin after hemorrhagic shock in rats. J Surg Res. 2013;179:115-24

39. Heyland DK, Elke G, Cook D, Berger MM, Wischmeyer PE, Albert M, et al. Glutamine and Antioxidants in the Critically III Patient: A Post Hoc Analysis of a Large-Scale Randomized Trial. J Parenter Enter Nutr. 2015;39:401-9.

40. Aksu U, Bezemer R, Yavuz B, Kandil A, Demirci C, Ince C. Balanced vs unbalanced crystalloid resuscitation in a near-fatal model of hemorrhagic shock and the effects on renal oxygenation, oxidative stress, and inflammation. Resuscitation. 2012;83:767-73.

41. Hwabejire JO, Lu J, Liu B, Li Y, Halaweish I, Alam HB. Valproic acid for the treatment of hemorrhagic shock: A dose-optimization study. J Surg Res. 2014; 186:363-70

42. Dekker SE, Sillesen M, Bambakidis T, Andjelkovic AV, Jin G, Liu B, et al. Treatment with a histone deacetylase inhibitor, valproic acid, is associated with increased platelet activation in a large animal model of traumatic brain injury and hemorrhagic shock. J Surg Res. 2014;190:312-8.

43. Jellestad L, Fink T, Pradarutti S, Kubulus D, Wolf B, Bauer I, et al. Inhibition of glycogen synthase kinase (GSK)-3- $\beta$ improves liver microcirculation and hepatocellular function after hemorrhagic shock. Eur J Pharmacol. 2014;724:175-84.

44. Tomar RPS, Vasudevan R. Metabolic acidosis due to inhaled salbutamol toxicity: A hazardous side effect complicating management of suspected cases of acute severe asthma. Med J Armed Forces India. 2012;68:242-4.

45. Rohrig R, Wegewitz C, Lendemans S, Petrat F, De Groot H. Superiority of acetate compared with lactate in a rodent model of severe hemorrhagic shock. J Surg Res. 2014;186:338-45.
46. Cossu AP, Mura P, Giudici LM De, Puddu D, Pasin L, Evangelista M, et al. Vasopressin in Hemorrhagic Shock: A Systematic Review and Meta-Analysis of Randomized Animal Trials. BioMed Res Int. 2014;2014.

47. Lin GS, Chou TH, Wu CY, Wu MC, Fang CC, Yen ZS, et al. Target blood pressure for hypotensive resuscitation. Injury. 2013;44:1811-5.

48. Yu TC, Yang FL, Hsu BG, Wu WT, Chen SC, Lee RP, et al. Deleterious effects of aggressive rapid crystalloid resuscitation on treatment of hyperinflammatory response and lung injury induced by hemorrhage in aging rats. J Surg Res. 2014;187:587-95.

49. Dubin A, Pozo MO, Casabella CA, Murias G, Pálizas Jr F, Moseinco MC, et al. Comparison of $6 \%$ hydroxyethyl starch 130/0.4 and saline solution for resuscitation of the microcirculation during the early goal-directed therapy of septic patients. J Crit Care. 2010;25:659. e1-659.e8.

50. Wang P, Li Y, Li J. Hydroxyethyl starch 130/0.4 prevents the early pulmonary inflammatory response and oxidative stress after hemorrhagic shock and resuscitation in rats. Int Immunopharmacol. 2009;9:347-53.

51. Lee CC, Chang IJ, Yen ZS, Hsu CY, Chen SY, Su CP, et al. Delayed Fluid Resuscitation in Hemorrhagic Shock Induces Proinflammatory Cytokine Response. Ann Emerg Med. 2007:49:37-44.

52. Chien JC, Jeng MJ, Soong WJ, Hwang B. Effects of fluid resuscitation on cerebral tissue oxygenation changes in a piglet model of hemorrhagic shock. J Chinese Med Assoc. 2011;74:448-54.

53. Kim D-R, Yang S-H, Sung J-H, Lee S-W, Son B-C. Significance of intracranial pressure monitoring after early decompressive craniectomy in patients with severe traumatic brain injury. J Korean Neurosurg Soc. 2014;55:26-31.

54. Mole TB, Maciver K, Sluming V, Ridgway GR, Nurmikko TJ. Specific brain morphometric changes in spinal cord injury with and without neuropathic pain. Neurolmage Clin. 2014;5:28-35.

55. Hohl A, Gullo JDS, Silva CCP, Bertotti MM, Felisberto F, Nunes JC, et al. Plasma levels of oxidative stress biomarkers and hospital mortality in severe head injury: A multivariate analysis. J Crit Care. 2012;27:523. e11-523.e19.

56. Lichter-Konecki U, Nadkarni V, Moudgil A, Cook N, Poeschl J, Meyer MT, et al. Feasibility of adjunct therapeutic hypothermia treatment for hyperammonemia and encephalopathy due to urea cycle disorders and organic acidemias. Mol Genet Metab. 2013;109:354-9.

57. Ortiz D, Barros M, Yan S, Cabrales P. Resuscitation from hemorrhagic shock using polymerized hemoglobin compared to blood. Am J Emerg Med. 2014:32:248-55.

58. Curry N, Davis PW. What's new in resuscitation strategies for the patient with multiple trauma? Injury. 2012;43:1021-8.

59. Vlachou E, Gosling P, Moiemen NS. Hydroxyethylstarch supplementation in burn resuscitation - A prospective randomised controlled trial. Burns. 2010;36:984-91.

60. Sun YX, Wu XS, Gao Z, Wang F, Liu S, Chen XL. Effect of $200 \mathrm{mEq} / \mathrm{L} \mathrm{Na}+$ hypertonic saline resuscitation on systemic inflammatory response and oxidative stress in severely burned rats. J Surg Res. 2013;185:477-84.

61. Fodor L, Fodor A, Ramon Y, Shoshani O, Rissin Y, Ullmann Y. Controversies in fluid resuscitation for burn management: Literature review and our experience. Injury. 2006:37:374-9.

62. Arlati S, Storti E, Pradella V, Bucci L, Vitolo a, Pulici M. Decreased fluid volume to reduce organ damage: A new approach to burn shock resuscitation? A preliminary study. Resuscitation. 2007;72:371-8.

63. Guidry C, Gleeson E, Simms ER, Stuke L, Meade P, McSwain NE, et al. Initial assessment on the impact of crystalloids versus colloids during damage control resuscitation. J Surg Res. 2013;185:294-9.

64. Yu YH, Gong SP, Sheng C, Zhao KS, Lodato RF, Wang CH. Increased survival with hypotensive resuscitation in a rabbit model of uncontrolled hemorrhagic shock in pregnancy. Resuscitation. 2009;80:1424-30.

65. O'Malley CMN, Frumento RJ, Hardy MA, Benvenisty Al, Brentjens TE, Mercer JS, et al. A Randomized, Double-Blind Comparison of Lactated Ringer's Solution and $0.9 \% \mathrm{NaCl}$ During Renal Transplantation. Anesth Analg. 2005;100:1518-24.

66. Maitland K, Kiguli S, Opoka RO, Engoru C, Olupot-Olupot P, Akech SO, et al. Mortality after Fluid Bolus in African Children with Severe Infection. N Engl J Med. 2011;364:2483-95.

67. Shaw AD, Bagshaw SM, Goldstein SL, Scherer LA, Duan M, Schermer CR, et al. Major Complications, Mortality, and Resource Utilization After Open Abdominal Surgery: 0.9 \% Saline Compared to Plasma-Lyte. Ann Surg. 2012;255:821-9.

68. Annane D, Siami S, Jaber S, Martin C, Elatrous S, Declère AD, et al. Effects of fluid resuscitation with colloids vs crystalloids on mortality in critically ill patients presenting with hypovolemic shock: The cristal randomized trial. JAMA. 2013;310:1809-17. 
69. Rasmussen KC, Johansson PI, Højskov M, Kridina I, Kistorp T, Thind P, et al. Hydroxyethyl Starch Reduces Coagulation Competence and Increases Blood Loss During Major Surgery: Results From a Randomized Controlled Trial. Ann Surg. 2014:259:249-54.

70. Chowdhury AH, Cox EF, Francis ST, Lobo DN. A Randomized, Controlled, DoubleBlind Crossover Study on the Effects of 2-L Infusions of $0.9 \%$ Saline and PlasmaLyte 148 on Renal Blood Flow Velocity and Renal Cortical Tissue Perfusion in Healthy Volunteers. Ann Surg. 2012;256:18-24.

Submit your next manuscript to BioMed Central and we will help you at every step:

- We accept pre-submission inquiries

- Our selector tool helps you to find the most relevant journal

- We provide round the clock customer support

- Convenient online submission

- Thorough peer review

- Inclusion in PubMed and all major indexing services

- Maximum visibility for your research

Submit your manuscript at www.biomedcentral.com/submit 